an agreed decision to deactivate the ICD with the patients/ their family.

In these situations, patients and families placed different weights to the clinical team on the benefits and harms of leaving the ICD active versus deactivated, often because of strong preferences or intrinsic values related to pursuing treatments.

National guidance exists about factors to consider when making decision about deactivation of an ICD at end-of-life. However, staff experienced conflict between their wish to deliver medically appropriate but personalised care.

The teams were fluently able to discuss the harms that can occur as a result of leaving an ICD active including the pain from shocks and distress witnessing this. However, further consideration of real-time harms that were occurring as a result of deactivation discussions was crucial to reaching a shared decision to leave these ICDs active, unless preferences changed or the ICD fired causing distress.

The particular harms included: deactivation becoming the focus of encounters rather than other issues such as symptoms (often patient led); loss of trust in patient-clinician relationships because of (perceived) failure to recognise the importance of the individuals values/perspective; time taken for further discussions in context of time as a scarce resource/precious in end of life situations.

Our experiences and practice evolve with each case, but being mindful of current versus potential future harms, and articulating these, has been helpful in reaching shared agreed decisions to leave some ICDs active at end-of-life.

\section{ADVANCE CARE PLANNING: STAFF PERCEPTIONS OF PATIENTS RIGHTS, CHOICES AND PREFERENCES}

Matthew Doré, Phil Moore, Derek Willis. Severn Hospice

\subsection{6/bmjspcare-2019-ASP.95}

Background Advance care planning (ACP) is a process of formal decision making and documentation for future reference. For this to be communicated effectively nuances such as the difference between; 'Choice', 'Preference' and 'Rights' are paramount for decision making and understanding. This communication need has to be present on both sides of the consultation table.

Aim To explore the perception and understanding of the terms; 'Choice', Preference' and 'Rights' of the palliative care multidisciplinary team in relation to aspects of ACP.

Methodology An electronic survey completed by clinical staff within Severn Hospice over a week period.

Results There were 32 respondents from 8 different job roles. $69 \%$ (22) stated 'place of death' as a 'Preference' with $28 \%$ (9) stating it a 'Choice'. Exploring 'DNACPR' demonstrated; 'Choice' 39\% (12)/'Preference' 29\% (8)/'Right' 35\% (11). Decisions regarding 'refusing care' were mostly seen as a 'Right' $(62 \% \mathrm{n}=20)$ whereas 'requesting aspects of care' such as admission and medications were perceived as 'Choice' $(40 \% n=13)$ or 'Preference' $(37 \% n=12)$.

The qualitative aspect asked for perceived definitions of 'Choice', 'Preference' and 'Rights' of which we split into multiple themes. 'Choice' had a predominance of the themes of 'options' and 'information'. 'Preference' had predominant themes of 'options' and 'if possible'. Rights had a more legal focus/aspect.
Conclusion There's considerable heterogeneity in the understanding of the terms; 'Choice', Preference', and 'Rights', and even more so between the terms 'Choice' and 'Preference'. Given this is conducted upon hospice staff this gives a measure for concern as potentially conflicting messages and understanding could be communicated.

\section{DNACPR PRACTICE: HAS THE TRACEY JUDGEMENT MADE A DIFFERENCE?}

Natasha Freeman, Beverley Clarke, Michael Macfarlane, Derek Willis. West Midlands Collaboration Actioning Research in End of Life and Supportive Care

\subsection{6/bmjspcare-2019-ASP.96}

Background A study earlier this year ${ }^{1}$ suggested that the 2014 Court of Appeals decision (The Tracey Judgement) had led to Do Not Attempt Cardiopulmonary Resuscitation (DNACPR) decisions being discussed more frequently with patients and their families in the hospice setting but there was a lack of clarity on what physical or psychological harm these discussions could cause.

We aimed to survey current practice amongst non-palliative care doctors and Clinical Nurse Specialists (CNS) regarding making and communicating DNACPR decisions, the impact of the Tracey judgement on their practice and their interpretations of harm.

Method An online anonymous survey was distributed to GPs, Consultants and CNSs in the West Midlands.

Results 89 responses were received (68\% GPs, 24\% consultants, 7\% CNSs). 90\% reported making DNACPR decisions on a regular basis. Reasons for not making DNACPR decisions included lack of time (50\%), responsibility lying with others (26\%) and fear of medicolegal consequences (13\%). Barriers to communicating DNACPR decisions included mental capacity of the patient (76\%), fear of causing distress $(24 \%)$ and lack of time (21\%). 51\% of respondents were aware of the 2014 Tracey judgement and 24\% reported it had changed their practice. Common themes regarding harm included a physical aspect (26\%), harm to patients (23\%), psychological distress (18\%) and emotional impact (9\%).

Conclusions These results suggest there are significant barriers to making and communicating DNACPR decisions and a lack of awareness about the Tracey judgement amongst non-palliative care doctors. Although some common themes emerged regarding interpretations of harm, the variation within this group suggests individual beliefs and values may influence interpretation of harm.

\section{REFERENCE}

1. Macfarlane M, Shayler S, Nelms L, WM CARES Group, et al. Tracey judgement and hospice DNACPR orders: steady as she goes or seismic change? BMJ Supportive \& Palliative Care 25 July 2018. doi:10.1136/bmjspcare-2018-001518

\section{4 'IF I'M GOING TO DIE, I WANT TO DIE BY 4PM:' THE IMPACT OF A TREATMENT WITHDRAWAL SCENARIO ON A SPECIALIST PALLIATIVE CARE TEAM}

Rosie Bronnert, Kathryn Lockwood. University Hospitals of Leicester

10.1136/bmjspcare-2019-ASP.97

Distress occurred within the hospital Specialist Palliative Care Team (SPCT) following the withdrawal of high flow oxygen 
at the request of a patient with capacity to make the relevant decisions.

These SPCT members work at a large specialist cardio-respiratory hospital and are often involved in discussions and decisions about, and the act of, withholding and withdrawal of treatment including oxygen and non-invasive ventilation.

This was the first occasion where team members specifically articulated distress, including moral distress, following their involvement in treatment withdrawal. Moral distress can be described as the 'psychological disequilibrium associated with knowing the ethical/appropriate action but being unable to take that action.'

Initial explorations of the distress identified only that this case 'felt different' to other withdrawal scenarios and team members used different vocabulary to describe their experiences and their impact. Within ethical literature, 'felt moral difference' is not considered to be a reliable guide to ethical conduct but nonetheless is important to address.

One team member used the American '4A's Approach to Moral Distress' (Ask, Affirm, Assess, Act) to help better understand their experience.

Relevant individual case factors included the very high flow rate of oxygen involved and the time-bound nature of the request. Analysis revealed different weights that individuals (patient and staff members) placed on autonomy and nonmaleficence as a source of tension. Furthermore, there were different views and values about individual and wider harms, including how these were explored and managed.

A combination of open communication, self-directed learning and reflection, enabled SPCT members to understand the source of their distress more clearly. Moral distress and a felt moral difference can impact on wellbeing, team functioning and ability to undertake specific work tasks. It is hoped this experience will enable the team to better articulate ethical dilemmas and understand their own perspectives.

\section{DO ETHICAL BARRIERS EXIST IN PROVIDING PALLIATIVE CARE TO THE HOMELESS, AND CAN THESE BE ADDRESSED WITH EXISTING HEALTHCARE SERVICES AND PROVISIONS?}

Sam Oldfield, Kirsty Moreton. University of Keele

10.1136/bmjspcare-2019-ASP.98

Background Average life expectancy in the homeless population is 47, and rates of homelessness are increasing significantly. With a high disease burden, these patients may benefit from palliative input, but historically there have been barriers to effective care.

Methods From consequentialist, virtue, and care ethics perspectives, two questions are addressed. Firstly, whether a coercive approach can be justified in a population who are traditionally reluctant to seek medical help, but may benefit greatly from treatment. Secondly, whether existing palliative services are appropriate for this group, or if there is ethical justification for a bespoke service, separate from mainstream healthcare.

Results Homelessness can be shown to effect the ability to make informed choices. Although there is ethical precedent for paternalistic approaches to health in such cases, for this population cultural capital, and so informed decision making, can be improved. We should therefore aim to increase the agency of homeless people, rather than further diminishing their rights.
Homeless people are often reluctant to engage with health services, and the care they receive is sub optimal. We should therefore avoid over medicalising end of life for this population, and focus on community based measures of care, which may emphasize social and psychological support over medical treatments.

Conclusion The homeless have not seen many of the health benefits of improved public health and primary prevention measures, and as such their life expectancy has remained static while others has improved. We frequently talk about a biopsychosocial model to health, but the focus is primarily on a biological approach. In this population, the focus should be reversed, with an emphasis on maintaining important social relationships and the psychological burden of disease in their situation.

\section{Global Palliative Care | Poster 76}

\begin{tabular}{l|l}
\hline 76 & 'WE TRY TO TRANSMIT PSEUDO STRENGTH TO OUR \\
KIDS; IF WE ARE BROKEN, THEY WILL BE BROKEN AS \\
WELL': NATURE OF THE DIALOGUE BETWEEN MOTHERS, \\
GRANDMOTHERS AND CHILDREN WITH LEUKAEMIA IN \\
PALESTINE
\end{tabular}

Maha Atout, Bernie Carter. Philadelphia University, Edge Hill University

\subsection{6/bmjspcare-2019-ASP.99}

Background Mothers of children with life-limiting illnesses describe facing challenges such as sometimes finding it difficult to communicate with their children, for example when their children become irritable due to their illnesses. This study explored the experience of communicating regarding the care of children with cancer, from the perspective of physicians, nurses, mothers, grandmothers and children in Palestine. This paper reports on the perceptions of the mothers and the grandmothers.

Methods This study employed an ethnographic, collective, qualitative case study approach. It was conducted in one oncology unit in a Palestinian hospital. Two data collection methods were employed: participant observation and semistructured interviews.

Results The study generated 70 hours of observation and 35 interviews; physicians $(n=5)$, nurses $(n=11)$, children aged 6-18 $(n=6)$, mothers $(n=7)$ and grandmothers $(n=6)$. Findings: The mothers and grandmothers stated that they pretended to be strong in front of their children to prevent them from feeling distressed by witnessing their mother's suffering and grieving. Protecting children from seeing their mothers' distress was thought to be essential to help children face their illness and their own suffering. Mothers talked to their children about their children's strengths rather than the deprivations caused by their illnesses. Although they did not feel strong, the mothers tried to transfer their own strength to their children to strengthen them and protect them from being broken.

Conclusions Being the mother of a child with cancer is clearly distressing and they suffer along with their child. Their maternal role drives them to conceal their own grief and their conversations with their children are strengths-based. There is clearly a role for nurses caring for families of children with cancer to support mothers and give them the opportunity to express and share their grief and distress. 